\title{
Zooplanktivory by Praunus flexuosus (Crustacea: Mysidacea): functional responses and prey selection in relation to prey escape responses
}

\author{
Markku Viitasalo*, Milla Rautio \\ Tvärminne Zoological Station, FIN-10900 Hanko, Finland \\ and
}

Department of Ecology and Systematics, Division of Hydrobiology, PO Box 17, FIN-00014 University of Helsinki, Finland

\begin{abstract}
Zooplankton feeding rates and prey selection of the mysid shrimp Praunus flexuosus were studied in single and multiple prey species experiments. Functional responses of $P$. flexuosus were determined for 2 copepod species, Acartia spp. (adults) and Eurytemora affinis (adult females), and 2 cladoceran species, Pleopsis polyphemoides and Bosmina longispina maritima. Feeding rates were highest with $P$. polyphemoides, intermediate with B. longispina maritima and Acartia spp. and lowest with $E$. affinis. Videofilming of the prey species subjected to an artificial water flow confirmed that $E$. affinis displays a stronger escape response than Acartia spp., and that cladocerans cannot withstand a water current. In a prey selection experiment with Acartia spp. and E. affinis, P. flexuosus clearance rates of Acartia spp. were suppressed in the presence of $E$. affinis, suggesting an interference effect from $E$. affinis. In another multiple prey species experiment with Acartia spp. and P. polyphemoides, the mysids fed intensively on cladocerans, regardless of whether the cladocerans occurred alone or with copepods. In contrast, predation on Acartia spp. significantly declined when cladocerans were offered as alternative food (at high concentration). We suggest that $P$. flexuosus can capture cladocerans by creating a suspension feeding current, whereas the evasive copepods need to be perceived and attacked individually. At low prey concentration, P. flexuosus feeds opportunistically by using both feeding modes, and the apparent 'selectivity' mainly reflects the escape capabilities and morphological defences of the prey species; at high prey concentration, $P$. flexuosus may show true selection by switching from omnivorous feeding to suspension feeding on cladocerans.
\end{abstract}

KEY WORDS: Mysid shrimps - Praunus flexuosus - Zooplanktivory - Functional response Prey selection - Prey switching - Escape reaction B Baltic Sea

\section{INTRODUCTION}

The general 'predation vulnerability' (Pastorok 1981, Greene 1986) of different planktonic prey species can be estimated from planktivores' functional responses to each prey. However, extrapolating functional responses determined in single prey situations to more natural conditions is not straightforward, because

- Address for correspondence: Department of Ecology and Systematics, Division of Hydrobiology, PO Box 17, FIN00014 University of Helsinki, Finland.

E-mail:markku.viitasalo@helsinki.fi predators may modify their behaviour when several prey species become available. A potential way of adapting to multi-species situations is prey switching, i.e. preying disproportionately more intensively on the most abundant prey species (e.g. Murdoch 1969, Lawton et al. 1974). This behaviour will enable efficient feeding on one prey type at a time, but it will also allow sufficient dietary variation for the predator (Kiorboe et al. 1996). In the pelagic environment, prey switching has been reported in predators that can alter their feeding behaviour from one mode to another. For instance, certain omnivorous copepods switch from suspension feeding on phytoplankton cells (diatoms) to 
raptorial feeding on animal prey (ciliates or copepod nauplii) in response to changes in prey availability (Landry 1981, Kiørboe et al. 1996). Among larger planktivores, similar flexibility has been observed for northern anchovy Engraulis mordax, which shifts from zooplanktivory to filter feeding on phytoplankton when zooplankton densities are exceptionally low (Leong \& O'Connell 1969).

Mysid shrimps are abundant nectobenthic and sublittoral crustaceans in many lacustrine and marine ecosystems. In the Baltic Sea, their impact on zooplankton populations has been considered significant (Rudstam et al. 1989, 1992, Hansson et al. 1990, Rudstam \& Hansson 1990, Uitto et al. 1995, Nordström 1997), but their prey selection has not been extensively studied. The existing marine studies are also somewhat at odds with lacustrine studies: while many freshwater studies suggest that mysids prey more readily on cladocerans than on copepods (Lasenby \& Langford 1973, Cooper \& Goldman 1980, Bowers \& Vanderploeg 1982, Grossnickle 1982, Ramcharan et al. 1985, Nero \& Sprules 1986), certain Baltic results suggest that mysids (Mysis mixta) prefer a number of copepod taxa over cladocerans (Mohammadian et al. 1997). Furthermore, mysids are predators which have the potential to show prey switching, because they feed on small prey items by suspension feeding but capture larger prey raptorially (Bowers \& Grossnickle 1978, Cooper \& Goldman 1980, Mauchline 1980, Siegfried \& Kopache 1980, Grossnickle 1982). However, prey switching has not previously been explicitly studied in mysids.

The purpose of the present study was to investigate prey selection and prey switching in mysid shrimps. Also, we wanted to find out how mysids may cope with changes in Baltic zooplankton community composition. There are 7 mysid species in the Baltic Sea. Of these, Mysis mixta and the 2 sibling species of $M$. relicta are confined to the open sea, whereas Neomysis integer, Praunus flexuosus, $P$. inermis and Hemimysis anomala occupy shallower habitats (e.g. Segerstråle 1962, Rudstam et al. 1986, Salemaa et al. 1986, 1990, Väinölä 1992, Salemaa \& Hietalahti 1993). We chose to experiment with $P$. flexuosus, because it is abundant, easy to collect and handle in the laboratory, and able to feed on a range of different prey types, including copepods and cladocerans (Nordström 1997). All mysids feed omnivorously on zooplankton, phytoplankton and detritus, but we wanted to study interactions with animal prey, because these are important food for $P$. flexuosus during its main growth period in summer (Nordström 1997). Following Landry (1981) and Kiorboe et al. (1996), we hypothesised that prey switching may occur in situations where different prey need to be captured with different foraging modes. With relatively similar prey types, in contrast, the ingestion rates should simply reflect the differences in prey escape capabilities and morphological defences. These hypotheses were examined by single and multiple prey species experiments and by investigating the escape capabilities of the prey species with videographic methods.

\section{MATERIALS AND METHODS}

Mysid and zooplankton collection. The material for our experiments was collected in the SW archipelago of Finland $\left(59^{\circ} 47^{\prime} \mathrm{N}, 23^{\circ} 16^{\prime} \mathrm{E}\right)$ during July 1997. Mysids were collected from the sublittoral using an arm net which was pulled through macroalgal vegetation (mainly Fucus vesiculosus). After capture, mysids were immediately brought into a $13^{\circ} \mathrm{C}$ temperaturecontrolled room where adult females with a marsupium (2.2 to $2.5 \mathrm{~cm}$ total length) were transferred into filtered seawater $\sim 12 \mathrm{~h}$ before the experiments.

Zooplankton was collected daily from a $35 \mathrm{~m}$ deep archipelago area (ca $500 \mathrm{~m}$ from the shore) using a Hensen-type plankton net (diameter $60 \mathrm{~cm}$, mesh size $200 \mu \mathrm{m}, 1 \mathrm{l}$ cod end), which was hauled 3 to 5 times from $\sim 30 \mathrm{~m}$ depth to the surface. Water was stratified and temperature varied between 4 and $23^{\circ} \mathrm{C}$ in the 0 to $30 \mathrm{~m}$ layer. The zooplankton sample was placed in an insulated box with 15 I of seawater collected at $\sim 5,10$ and $20 \mathrm{~m}$ depths. Within $30 \mathrm{~min}$ after capture, zooplankton was brought into the $13^{\circ} \mathrm{C}$ room. The dominant calanoids Acartia spp. and Eurytemora affinis and cladocerans Pleopsis polyphemoides and Bosmina Iongispina maritima were chosen as prey. The copepods mainly represented adult stages that were abundant in the water during the experiments. In Acartia spp., females and males (but also some Stage 5 copepodites) were selected in E. affinis only egg-carrying females were chosen. Copepods were carefully transferred into filtered seawater and were left to acclimate to the experimental temperature overnight. Cladocerans were left in an aerated container overnight, and actively swimming individuals were transferred to the experimental bottles $\sim 30 \mathrm{~min}$ before the experiments. During selection of the cladocerans, the bottles were lit from below, which prevented the specimens from being trapped by the film at the water's surface

Carbon contents of the prey species were determined using the high temperature combustion method (Salonen 1979) from live individuals that represented sizes and developmental stages similar to those used in the experiments. The carbon contents (in $\mu \mathrm{g} \mathrm{C}$ ind. ${ }^{-1}$ ) were 3.08 for Acartia spp. ( $S D=0.62, n=16), 5.14$ for Eurytemora affinis ( $\mathrm{SD}=1.12, \mathrm{n}=10), 1.27$ for Pleopsis polyphemoides $(\mathrm{SD}=0.40, \mathrm{n}=10)$ and 1.82 for Bosmina longispina maritima ( $\mathrm{SD}=0.34, \mathrm{n}=18$ ). 
Table 1. Functional response experiments with Acartia spp., Eurytemora affinis, Pleopsis polyphemoides and Bosmina longispina maritima: numeric (ind. $\mathrm{I}^{-1}$ ) and carbon concentra-

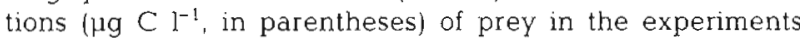

\begin{tabular}{|cccc|}
\hline Acartia spp. & E. affinis & $P$ polyphemoides & $\begin{array}{c}\text { B. longispina } \\
\text { maritima }\end{array}$ \\
\hline $4.3(13.4)$ & $4.3(22.3)$ & $13.0(16.6)$ & $13.0(23.7)$ \\
$13.0(40.2)$ & $13.0(67.0)$ & $43.5(55.2)$ & $43.5(79.1)$ \\
$26.1(80.3)$ & $26.1(134.1)$ & $87.0(110.4)$ & $87.0(158.3)$ \\
$43.5(133.9)$ & $43.5(223.5)$ & $130.4(165.7)$ & $130.4(237.4)$ \\
$60.9(187.5)$ & $60.9(312.9)$ & $173.9(220.9)$ & $173.9(316.5)$ \\
$87.0(267.8)$ & $87.0(447.0)$ & $260.9(331.3)$ & $260.9(474.8)$ \\
\hline
\end{tabular}

Functional response experiments. All predation experiments were conducted in $1.15 \mathrm{l}$ bottles in $0.2 \mu \mathrm{m}$ filtered seawater, under dimmed room lighting. Concentrations of Acartia spp. and Eurytemora affinis were varied from 5 to 100 ind. bottle ${ }^{-1}$ and concentrations of Pleopsis polyphemoides and Bosmina longi-spina maritima from 15 to 300 ind bottle ${ }^{-1}$ (Table 1). Most of these concentrations may occur in the field (Viitasalo 1992, Viitasalo et al. 1995), although the highest concentrations may only occur in very localised patches. Because mysids apparently interfere with each other's predation in experimental containers ( $S$. Hansson, University of Stockholm, pers. comm.), only 1 Praunus flexuosus was placed in each bottle. Bottles were sealed with a plastic film to prevent air bubbles and placed in a plankton wheel rotating at $0.5 \mathrm{rpm}$. Three to 5 replicates were made with copepods and 3 to 7 with cladocerans. After the incubation, the specimens were killed with Lugol's solution, the mysids were measured, and the remaining copepods and cladocerans were counted under a binocular microscope.

The functional response curves were determined by fitting 3 alternative models to the data: linear $\left(y=y_{0}+\right.$ $a x)$, exponential rise to maximum $\left[y=a\left(1-e^{-b x}\right)\right]$ and a sigmoidal model $\left\{y=a /\left[1+\left(x / x_{0}\right)^{b}\right]\right\}$. These models represent Holling Type 1,2 and 3 functional response models, respectively (Holling 1959). A more complicated model was chosen only if the variation explained $\left(r^{2}\right)$ was $>5 \%$ higher than the $r^{2}$ of the simpler model. The function parameters and $r^{2}$ values were estimated using the graphing program SigmaPlot 4.0.

A problem with studying functional responses in bottles is that the prey concentration cannot be kept constant. The experiments therefore need to be relatively short, so that prey are not depleted before the end of the incubation, but long enough to provide a clear predation signal at each concentration. The duration of our experiments was $2 \mathrm{~h}$, which was chosen as most appropriate according to preliminary experiments with durations of 1,2 and $4 \mathrm{~h}$.
Table 2. Prey selection experiment 1 Ratio of Acartia spp. to Eurytemora affinis and numeric (ind. $\mathrm{I}^{-1}$ ) and carbon concentrations ( $\mu \mathrm{g} \mathrm{Cl}^{-1}$, in parentheses) of prey in various treatments

\begin{tabular}{|llll|}
\hline $\begin{array}{l}\text { Acartia spp.: } \\
\text { E. affinis ratio }\end{array}$ & Acartia spp. & E. affinis & $\begin{array}{c}\text { Total } \\
\text { conc. }\end{array}$ \\
\hline $85: 15$ & $73.9(227.6)$ & $13.0(66.8)$ & $87.0(294.4)$ \\
$70: 30$ & $60.9(187.6)$ & $26.1(134.2)$ & $87.0(321.8)$ \\
$50: 50$ & $43.5(134.0)$ & $43.5(223.6)$ & $87.0(357.6)$ \\
$30: 70$ & $26.1(80.4)$ & $60.9(313.0)$ & $87.0(393.4)$ \\
$15: 85$ & $13.0(40.0)$ & $73.9(379.8)$ & $87.0(419.8)$ \\
\hline
\end{tabular}

Prey selection experiments. Prey selection of Praunus flexuosus was investigated with 2 different multi-species experiments: Acartia spp. with Eurytemora affinis, and Acartia spp. with Pleopsis polyphemoides. The first experiment was designed to examine possible prey switching in a situation where the dominant copepod species (here, Acartia spp.) is gradually replaced by a subdominant one ( $E$. affinis). In this experiment the total prey density was always 100 ind. bottle ${ }^{-1}$, but the Acartia spp.:E. affinis ratio was varied as follows: 85:15, 70:30, 50:50, 30:70, 15:85 (Table 2). Four replicate experiments were done for each combination. The effect of the alternative prey species on $P$. flexuosus' clearance rates was analysed with the analysis of covariance (ANCOVA, in the statistical package SYSTAT 5.03). In this analysis, we compared the clearance of Acartia spp. with and without E. affinis (i.e. results of the multiple prey experiment were compared with results of the functional response experiment); concentration of Acartia spp. was used as a covariate. A similar analysis was done also for $P$. flexuosus' clearance of $E$. affinis with and without Acartia spp. (with Eurytemora concentration as a covariate). Because saturation may hamper the interpretation of ANCOVA, clearly saturating prey concentrations i $>50$ ind. $\mathrm{l}^{-1}$ ) were excluded from the analyses.

Cladoceran populations often increase very rapidly in the field (e.g. Viitasalo et al. 1995). We therefore designed the second prey selection experiment to examine how mysid feeding rates change when cladocerans are introduced 'on top' of the copepod community. To reveal if prey concentration affects Praunus flexosus' selectivity, the experiment was performed at 2 prey densities: 30 Acartia spp. with 60 Pleopsis polyphemoids per bottle, and 100 Acartia spp, with $200 P$. polyphemoids per bottle (Table 3). Five replicates were done for both combinations. These 2 prey concentra tions are hereafter referred to as 'low food' and 'high food' conditions, respectively. The concentrations were chosen according to the single species functional response curves to represent situations where foraging on Acartia spp. should result in approximately similar 
Table 3. Prey selection experiment 2 with Acartia spp. and Pleopsis polyphemoides. Total numeric (ind. $\mathrm{1}^{-1}$ ) and carbon concentrations ( $\mathrm{gg} \mathrm{C} \mathrm{^{-1 }}$, in parentheses) of prey in various treatments

\begin{tabular}{|c|c|}
\hline Treatment & $\begin{array}{l}\text { Total prey } \\
\text { concentration }\end{array}$ \\
\hline \multicolumn{2}{|l|}{ 'Low food' conditions } \\
\hline Treatment 1 (30 Acartia spp. boltle ${ }^{-1}$ ) & $26.1(80.3)$ \\
\hline Treatment $2\left(60 P\right.$ polyphemoides bottle $\left.{ }^{-1}\right)$ & $52.2(66.3)$ \\
\hline $\begin{array}{l}\text { Treatment } 3 \text { (30 Acartia spp. and } 60 \\
\text { P. polyphemoides bottle }{ }^{-1} \text { ) }\end{array}$ & $78.3(146.6)$ \\
\hline \multicolumn{2}{|l|}{ 'High food' conditions } \\
\hline Treatment 1 (100 Acartia spp bottle ${ }^{-1}$ ) & $87.0(267.8)$ \\
\hline Treatment 2 (200 P polyphemoides bottle ${ }^{-1}$ ) & $173.9(220.9)$ \\
\hline $\begin{array}{l}\text { Treatment } 3 \text { (100 Acartia spp. and } 200 \\
\left.\text { P. polyphemoides bottle }{ }^{-1}\right)\end{array}$ & $260.9(488.7)$ \\
\hline
\end{tabular}

carbon ingestion as foraging on P. polyphemoides ('low food' conditions), and foraging on $P$. polyphemoides should give more carbon due to Acartia spp. saturation ('high food' conditions) (cf. Table 3 and 'Results').

Experiments with artificial flow. To investigate the escape capabilities of the prey species, we videofilmed the behaviour of Bosmina longispina maritima, Acartia spp. (adults) and Eurytemora affinis (ovigerous females) when subjected to an artificially created water flow. Pleopsis polyphemoides could not be filmed because it did not occur in plankton at the time these experiments were carried out. The experimental specimens were collected and handled as in the predation experiments. A Pasteur pipette (diameter of the opening $=1.5 \mathrm{~mm}$ ) was fixed vertically in a cubic 1 l Plexiglas aquarium filled with filtered seawater so that the tip of the pipette was $3.5 \mathrm{~cm}$ above the bottom of the aquarium. The pipette was connected to a silicon tube with the free end hanging $46 \mathrm{~cm}$ below the aquarium, which created a water flow to which the zooplankton reacted. When the water level was close to the tip of the pipette, more water was added and filming was continued (after the water turbulence had calmed down) until a sufficient number of observations was made. The filming was done in a $13^{\circ} \mathrm{C}$ temperature-controlled room, with 'Mintron' closed-circuit video cameras, using infrared light emitting diodes as a light source (Viitasalo et al. 1998). To enable measurements of velocities and distances in 3 dimensions, 2 cameras were fixed at right angles at $90 \mathrm{~cm}$ distance from the aquarium. The 2 images were combined on a monitor with a Panasonic digital image mixer, and recorded with a Panasonic video cassette recorder producing 50 frames $\mathrm{s}^{-1}$ Time in $1 / 100 \mathrm{~s}$ was recorded with a FOR-A video timer. After filming, the fre- quency of escapes and captures by the pipette during each interaction were determined from the films. An 'interaction' was here defined as a film sequence starting with an individual plankter being entrained in the flow and ending with the prey either escaping from the flow field, or being sucked into the pipette (after 1 or several sequential escapes). The reaction distance of the plankters from the pipette and their escape speeds (during the first $0.06 \mathrm{~s}$ of the escape) were measured using an image analysing program, 'Fisk-Pos' (L. W. Pedersen, Danish Institute for Fisheries Research). Positions of the plankters were followed frame by frame on the 2 perpendicular views, which resulted in $x-y-z$ and time coordinates for each escape and capture.

\section{RESULTS}

\section{Functional responses}

In most of the functional. response experiments, the food consumption of Praunus flexuosus increased linearly with increasing prey abundance. In Acartia spp., however, a sigmoid (Holling Type 3) model explained $75 \%$ of the variation (Fig. 1A), whereas the linear and Holling Type 2 models explained 67 and $70 \%$, respectively; saturation was approached at Acartia spp. concentrations exceeding $\sim 50$ ind. $\mathrm{l}^{-1}$. With Eurytemora affinis, Pleopsis polyphemoides and Bosmina longispina maritima, a linear model explained as much of the variation (within $-1 \%$ ) as the more complicated models (Fig. 1B-D). There was large variation in the consumption rates between $P$. flexuosus individuals: the ingestion rates varied 2- to 4 -fold at the highest prey concentrations (Fig. 1).

Fig. 2 shows the functional responses transformed to carbon ingested versus carbon available. The slope of the functional response was highest with Pleopsis polyphemoides, intermediate with Bosmina longispina maritima and lowest with Eurytemora affinis. Acartia spp. carbon ingestion was first similar to that of $P$. polyphemoides, but, with saturation at carbon concentrations above $\sim 150 \mu \mathrm{g} \mathrm{Cl}^{-1}$, Acartia spp. ingestion approached that of $B$. longispina maritima. From the sigmoid regression of Acartia spp., we can predict that Acartia ingestion will decline below that of $B$. longispina maritima at prey concentrations exceeding $-300 \mu \mathrm{C} \mathrm{I}^{-1}$ (Fig. 2).

\section{Prey selection}

In the first prey selection experiment, Acartia spp. was eaten at a higher rate than Eurytemora affinis, as 
Fig. 1 Praunus flexuosus. Functional responses with (A) Acar. tia spp. adults, (B) Eurytemora affinis ovigerous females, (C) Pleopsis polyphemoides and (D) Bosmina longispina maritima. Lines denote regressions through data; $r^{2}$ : variance explained
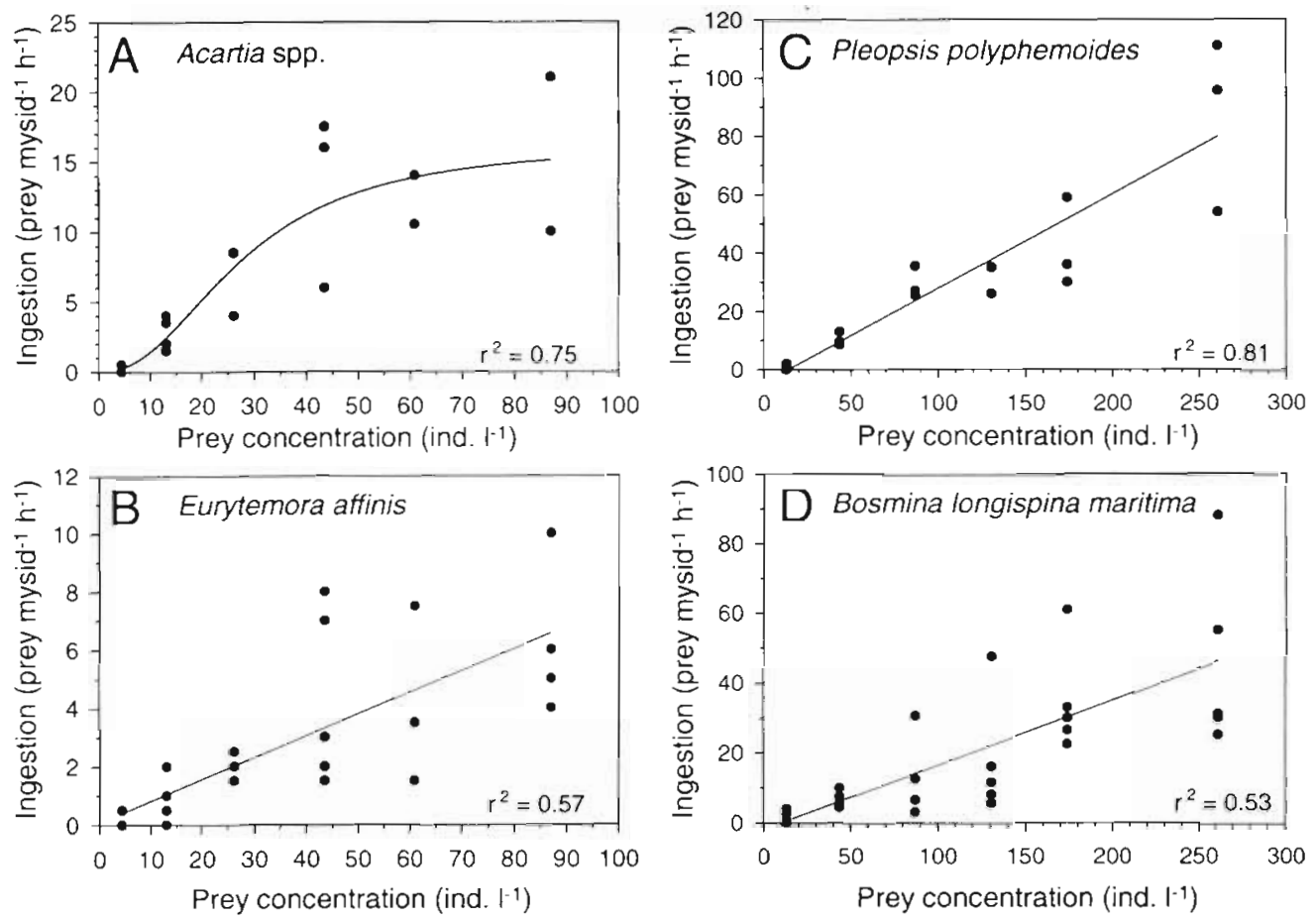

expected from the single prey experiments. Praunus flexuosus' feeding rate on $E$. affinis exceeded that on Acartia spp. only when the proportion of E. affinis was $>70 \%$ of the population density or carbon concentration (Fig. 3). Consequently, the total ingestion of copepods was significantly higher with an Acartia spp.dominated diet ( $>50 \%$ of the biomass in Acartia spp.) than with a $E$. affinis-dominated diet (Student's $t$-test value $=2.05, \mathrm{p}=0.049, \mathrm{df}=28$ ) (Fig. 4) .

The data do not clearly support the hypothesis of a stepwise switching from one prey species to another, although a curvilinear regression fits the Eurytemora affinis data (Fig. 3) somewhat better than a linear one $\left(\mathrm{r}^{2}=0.32\right.$ and 0.38 for the linear and third order polynomial regressions, respectively). We may examine the occurrence of prey switching in this experiment by studying the ratio of clearance rates $(F)$ of the 2 prey species (cf. Landry 1981). Fig. 5 shows the ratio of Acartia spp. and $E$. affinis clearance rates $\left(F_{\text {Acartia }}: F_{\text {Eury- }}\right.$ teruoral as a function of Acartia spp. concentration (expressed as percentage of total prey availability). The ratio does not increase, which suggests that Praunus flexuosus did not show prey switching between these 2 species. We may further examine this result by comparing the clearances of the 2 prey in single and multiple prey species experiments. Fig. 6 shows that the clearance of Acartia spp. was significantly lowered when $E$. affinis was provided as alternative food (ANCOVA, $\mathrm{p}=0.0015$ ), whereas the clearance of $E$. affinis remained unchanged regardless of whether they were offered alone or together with Acartia spp. (ANCOVA, $\mathrm{p}=0.837$ ). This suggests that there was a 1 -sided interference effect: the presence of E. affinis interfered with predation on Acartia spp. but the presence of Acartia spp. did not interfere with predation on $E$. affinis.

The second multiple prey experiment was designed to find out if Praunus flexuosus suppresses its feeding on copepods (Acartia spp.) when cladocerans (Pleopsis polyphemoides) are provided as additional food (or

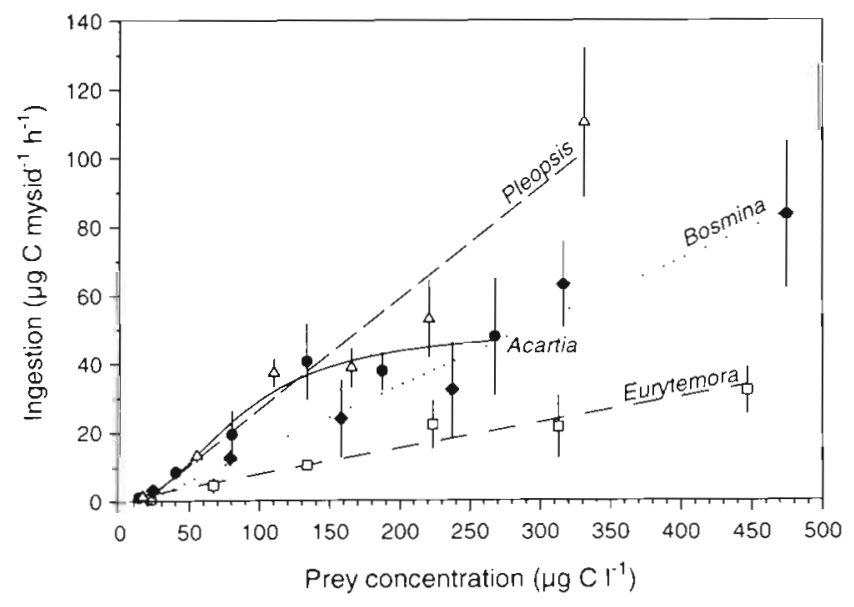

Fig. 2. Praunus flexuosus. Functional responses with Acartia spp., Eurytemora affinis, Pleopsis polyphemoides and Bosmina longispina maritima, shown as carbon weight ingested vs carbon weight available 

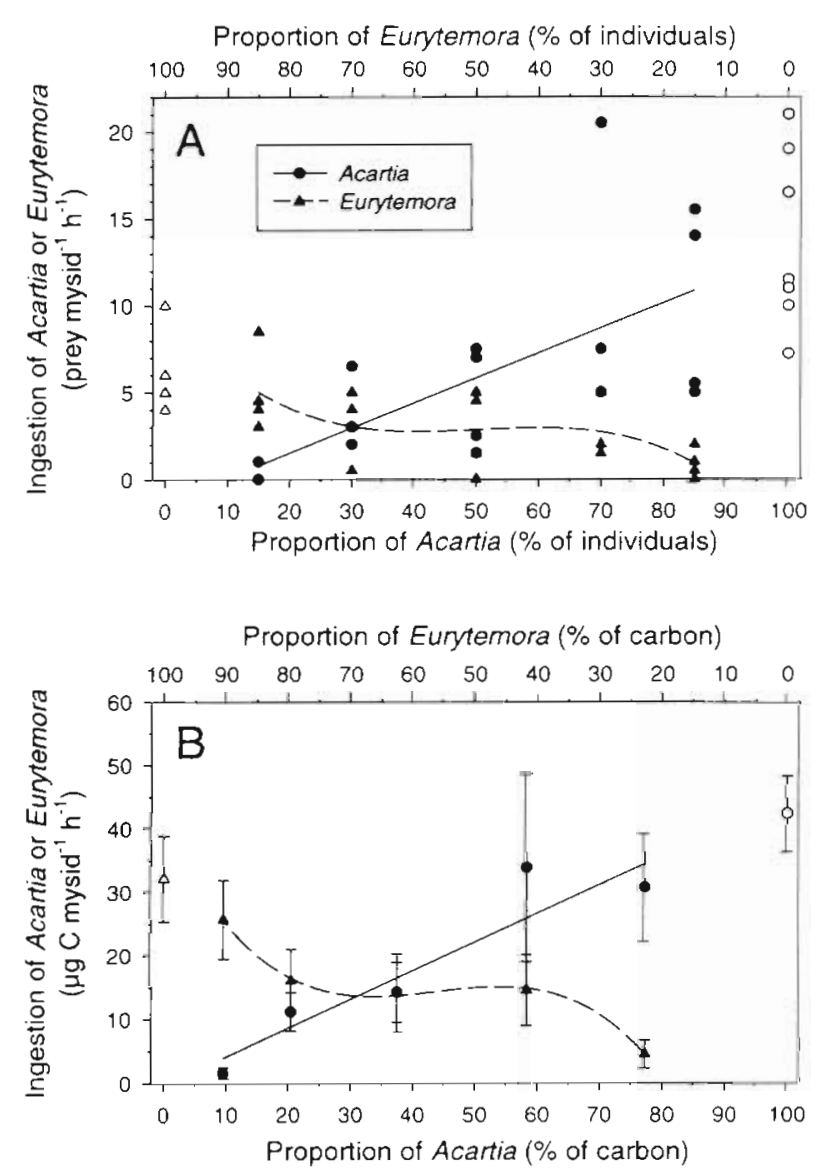

Fig. 3. Praunus flexuosus. Prey selection experiment 1 with Acartia spp. and Eurytemora affinis. Ingestion of Acartia spp. $(\bullet)$ and $E$. affinis ( 4 ) in relation to their proportional availability: (A) expressed as individuals ingested; (B) expressed as carbon weight ingested. Solid lines: linear regression through Acartia spp. data; dashed lines: a third order polynomial regression through $E$. affinis data. $(0, \Delta)$ Ingestion rates of Acartia spp. and $E$. affinis in single prey experiments (cf. Fig. 1), respectively. Symbols and vertical lines in (B): means and standard errors, respectively

vice versa). In 'low food' conditions (Fig. 7A), the ingestion of both prey remained at the same level, regardless of whether they were offered alone or together with the alternative prey species (Student's $t$ test, $p>0.10$ ). In 'high food' conditions, in contrast, Acartia spp. ingestion significantly decreased in the presence of $P$. polyphemoides (Student's $t$-test value $=$ 3.67, $\mathrm{p}=0.006, \mathrm{df}=8$ ), while $P$. polyphemoides ingestion remained at a similar level with or without Acartia spp. (Fig. 7B). However, if we take into account that the prey availability in the different treatments varied from 66 to $489 \mathrm{\mu g} \mathrm{Cl}^{-1}$, we note that the total ingestion showed a Holling Type 3 functional response (Fig. 8). Thus, in terms of carbon ingested, $P$. flexuosus seemed to be able to 'optimise' its foraging, regardless of prey mixture.

\section{Experiments with artificial flow}

The experiments with artificial flow revealed significant differences in the escape capabilities of the prey species. Both copepod species showed strong escape responses. The reaction distance from the opening of the pipette was very similar in Acartia spp. and Eurytemora affinis (averages $=0.52$ and $0.53 \mathrm{~cm}$, respectively; Fig. 9A), but the escape speed (Fig. 9B) was significantly higher in $E$. affinis than in Acartia spp. (averages $=5.51$ and $4.05 \mathrm{~cm}$ $\mathrm{s}^{-1}$, respectivelyi Student's $t$-test value $=2.29, \mathrm{p}=$ $0.026, \mathrm{df}=51$ ). Due to its higher initial speed, $E$. affinis also travelled a longer distance than Acartia spp. during each escape (averages $=0.34$ and $0.26 \mathrm{~cm}$, respectively).

A closer inspection of copepod behaviour revealed that the escaping Eurytemora affinis first performed a long series of small jumps and were finally released from the flow with a longer jump. In contrast, Acartia spp. were often repeatedly drawn towards the pipette, with the distance to the pipette gradually diminishing, and were finally captured. Consequently, the escape success of $E$. affinis was $91 \%$ (51 of 56 interactions), whereas Acartia spp. escaped only in $67 \%$ of the cases (33 of 49 interactions).

In complete contrast to the copepods, Bosmina longispina maritima were not able to resist the water current, and were always caught by the pipette if entrained in the flow. The escape success of $B$. longispina maritima was thus $0 \%$. The ability

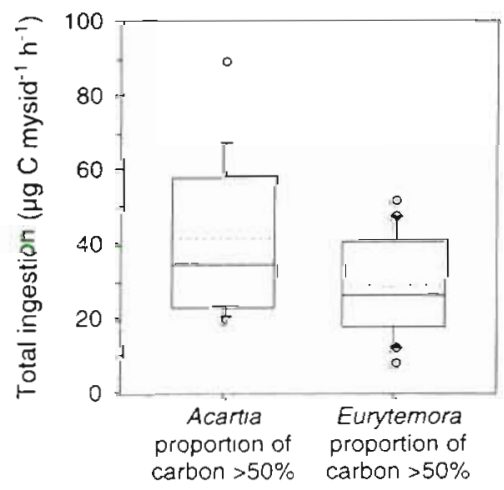

Fig. 4. Praunus flexuosus. Prey selection experiment 1 with Acartia spp. and Eurytemora affinis. Total carbon ingestion in treatments where the proportion of Acartia spp. of available carbon was $>50 \%$, and when the proportion of $E$. affinis of available carbon was $>50 \%$ (cf. Fig. 3B). Difference between data sets is statistically significant (Student's $t$-test value $=2.054, \mathrm{p}=0.049, \mathrm{df}=28$ ). Ends of boxes: 25th and 75th percentiles; ends of whiskers: 10 th and 90 th percentiles of the data; middle horizontal lines: medians; dotted lines: averages; circles: outliers outside 10 th and 90 th percentiles 


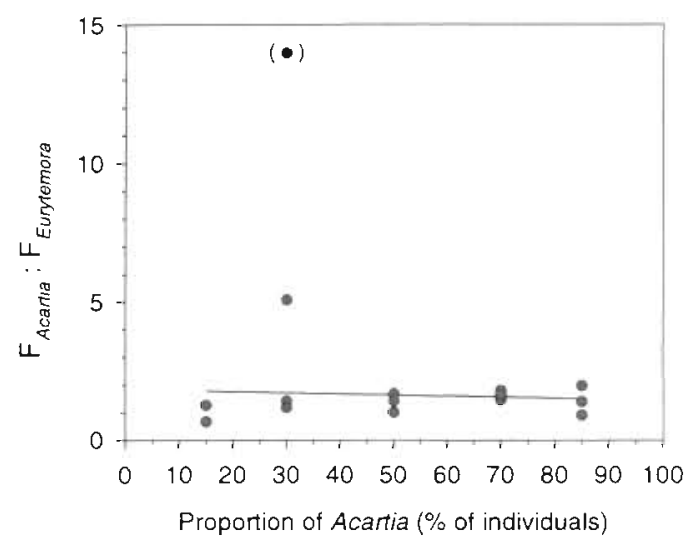

Fig. 5. Praunus flexuosus. Prey selection experiment 1 with Acartia spp. and Eurytemora affinis. Ratio of clearance rates of Acartia spp. and Eurytemora affinis ( $F_{\text {Acartia }} F_{\text {Eurytemoral, as }}$ a function of Acartia spp. concentration (expressed as percentage of prey available). Solid line: linear regression through data; the outlier (in parentheses) is not included in the regression
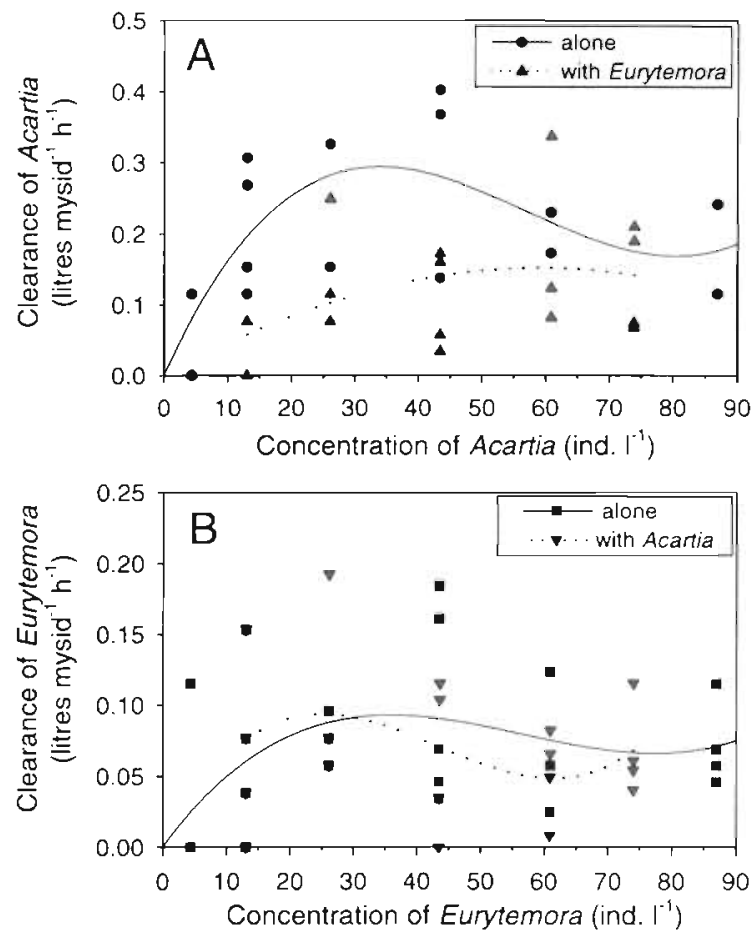

Fig. 6. Praunus flexuosus. Mysid clearance rates of (A) Acartia spp. and (B) Eurytemora affinis as a function of Acartia spp. and $E$. affinis availability, respectively. $(\bullet,-)$ Clearance rates in single prey experiments (cf. Fig. 1A, B); (4, - ) clearance rates in prey selection experiment 1 . Lines drawn as third order polynomial regressions through respective data

of Pleopsis polyphemoides to escape from pipette suction could not be investigated, but previous experiments (Viitasalo unpubl.) have shown that their locomotory powers are similar to or weaker than those of
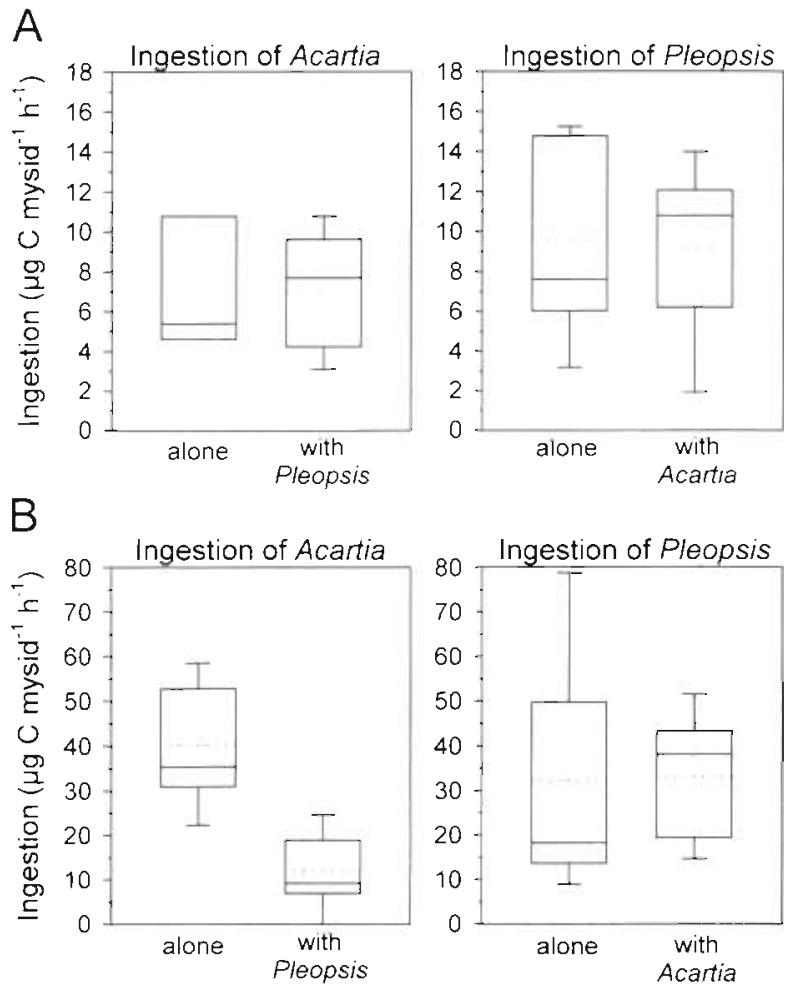

Fig. 7. Praunus flexuosus. Prey selection experiment 2 with Acartia spp. and Pleopsis polyphemoides. Ingestion rates when the prey were offered alone and when together with the alternative prey species. (A) 'Low food' conditions; (B) 'high food' conditions (see text for explanation). The difference between the ingestion of Acartia spp. data sets in (B) is statistically significant (Student's $t$-test value $=3.67, \mathrm{p}=0.006, \mathrm{df}=$ 8). Box-and-whisker plots as in Fig. 4

B. longispina maritima. We therefore believe that, with an identical experimental setup, the escape success of $P$. polyphemoides would have been $0 \%$ as well.

\section{DISCUSSION}

\section{Functional responses}

The functional response of a predator reflects the efficiency of the components of the predatory interaction, i.e. search, location, pursuit, attack, handling and ingestion (e.g. Holling 1959, Kerfoot 1978). Below the saturation level, the ingestion rate depends on the product of the encounter rate between predator and prey and the capture success of the predator. In the case of mysids feeding on zooplankton, the speed of the mysid (or its feeding current) mainly determines the encounter rate, because the mysid velocity is generally much higher than zooplankton swimming speed. If we assume a relatively constant mysid speed, the ingestion rate at each prey concentration thus depends 


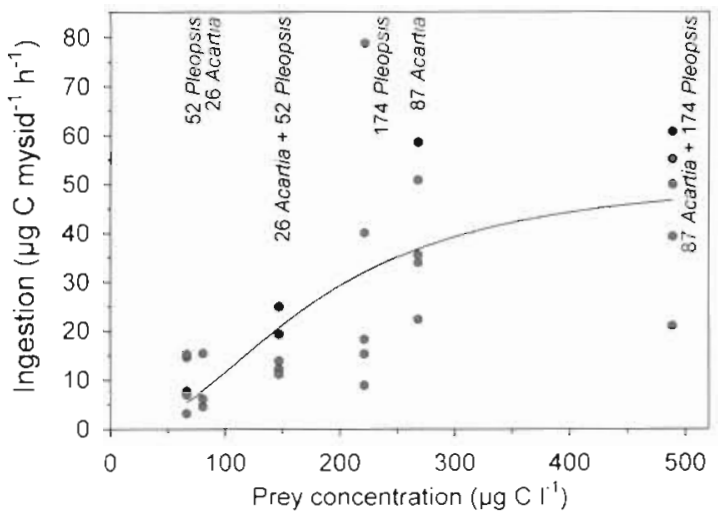

Fig. 8. Praunus flexuosus. Prey selection experiment 2 with Acartia spp. and Pleopsis polyphemoides. Total carbon ingestion plotted against carbon availability in various Acartia spp.-P. polyphemoides combinations. Solid line: sigmoidal (Holling Type 3) regression line through data; $r^{2}=0.514$. Prey concentration (ind. $\mathrm{l}^{-1}$ ) indicated above each treatment
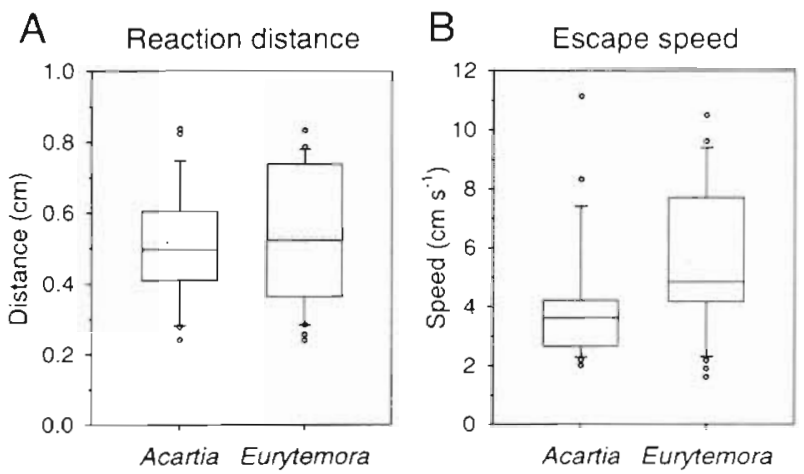

Fig. 9. Acartia spp. and Eurytemora affinis. Artificial flow experiment: (A) copepod reaction distances from the opening of the pipette $(B)$ escape speeds of the copepods during the first $0.06 \mathrm{~s}$ of the escape. The difference between the data sets in (B) is statistically significant (Student's $t$-test value $=2.29$, $\mathrm{p}=0.026, \mathrm{df}=51 \mathrm{l}$. Box-and-whisker plots as in Fig. 4

on the mysid's perceptive radius, capture success and handling time (Gerritsen \& Strickler 1977). These parameters, in turn, depend on prey characteristics, such as escape performance and body size and shape, as well as other morphological defences. In a single prey species experiment, we can therefore interpret the initial slope of the functional response to reflect the 'predation vulnerability' (sensu Pastorok 1981, Greene 1986) of each prey type to mysid predation.

The functional response experiments showed clear differences between predation vulnerabilities of the 4 prey species. Pleopsis polyphemoides was the most profitable species, both in terms of number of prey captured and amount of carbon ingested, Eurytemora affinis was the least profitable species, and Acartia spp. and Bosmina longispina maritima were intermedi- ate. With the wide range of prey concentrations studied, the functional responses were near-linear in $E$. affinis, $P$. polyphemoides and B. longispina maritima. This suggests that Praunus flexuosus feeding on these species rarely saturates in the field. In contrast, feeding on Acartia spp. saturated above -50 ind. $\mathrm{l}^{-1}$. Average concentrations of Acartia spp. normally remain below this level (e.g. Viitasalo 1992, Viitasalo et al. 1995), but many copepod species, including Acartia spp., occasionally show swarming behaviour, with densities

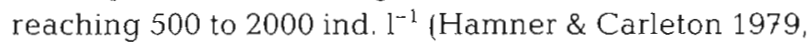
Ueda et al. 1983). If Acartia spp. form similar swarms in the Baltic Sea, P. flexuosus feeding on Acartia spp. could easily saturate.

The different prey vulnerabilities observed in predation experiments were consistent with the results of the pipette experiments. Whether the fluid flow created by a pipette simulates mysid feeding current can of course be questioned. However, in another experiment (Viitasalo et al. 1998), the reaction distance of Eurytemora affinis females from freely swimming mysids (Neomysis integer) was $0.45 \mathrm{~cm}$, which corresponds with the reaction distance of $E$. affinis observed in the present study $(0.53 \mathrm{~cm})$. This suggests that we can use pipette experiments to simulate mysid feeding current and to make comparisons between the escape capabilities of prey species. Based on our experiments, we suggest that, although Acartia spp. and E. affinis possessed similar sensory abilities (as characterised by their reaction distances to the pipette), E. affinis is a more difficult prey for Praunus flexuosus because of its stronger escape jump and better endurance during a long series of escapes. The difference between the vulnerabilities of copepods and Pleopsis polyphemoides can also be explained by the pipette experiments, which showed that small cladocerans (i.e. Bosmina longispina maritima) cannot resist the water flow. This agrees with the results of Szlauer (1965), Drenner et al. (1978) and Drenner \& McComas (1980), who have shown that cladocerans have less developed escape reactions than copepods. The higher survival of $B$. longispina mantima compared to $P$. polyphemoides, on the other hand, may be partly explained by its morphological and behavioural defences. Bosmina spp. possess a carapace that can be closed to protect the vulnerable appendages and soft abdomen, which provides some protection against predation (Kerfoot 1978). P. polyphemoides does not have a similar bivalve morphology, which probably makes it more vulnerable to invertebrate predation.

Our results agree with another Baltic study, in which the feeding of Mysis mixta was studied in mesocosms. Mohammadian et al. (1997) found that M. mixta ingests prey in the following order of preference: Pseudocalanus juveniles $\approx$ Acartia adults $\geq$ Bosmina $\approx$ Acartia juveniles $>$ Eurytemora adults and juveniles. 
These results, as well as ours, differ from North American lake studies, which suggest that Mysis relicta favours cladocerans over copepods (Lasenby \& Langford 1973, Cooper \& Goldman 1980, Bowers \& Vanderploeg 1982, Grossnickle 1982, Ramcharan et al. 1985, Nero \& Sprules 1986). This difference could be explained by assuming that the Baltic B. longispina maritima possesses more effective defences against predation than its freshwater relatives

\section{Prey selection}

When investigating prey 'selection' it is important to distinguish true selectivity from apparent selectivity. Apparent selectivity mainly reflects prey characteristics, such as escape behaviour and morphological defences, whereas true selection implies an active choice by the predator. True selectivity has been demonstrated in fish which can visually select prey according to prey size (Gardner 1981), colour contrast (Thetmeyer \& Kils 1995) or swimming pattern (Zaret 1980). To show true (pre-attack) selectivity, the predator must be able to identify each prey prior to attack and 'memorise' the profitability of different prey types. It is therefore less likely that invertebrate predators, especially those with less developed vision, show true selection. Invertebrate predators may instead optimise their foraging by more mechanistic behavioural patterns, such as prey switching.

Our experiments confirmed that, although Praunus flexuosus in most situations feeds opportunistically, it may under certain food conditions show true prey selection. In the experiment where Pleopsis polyphemoides and Acartia spp. were offered together (at high prey concentration), $P$. flexuosus clearly suppressed its feeding rates on copepods, whereas predation on cladocerans remained unchanged. We suggest that this was due to mysids switching to suspension feeding on cladocerans while decreasing capture attempts on the more evasive copepods. This kind of behavioural switching is analogous to that observed in the copepods Calanus pacificus and Acartia tonsa, which switch from suspension feeding on diatoms to raptorial feeding on animal prey (copepod nauplii or ciliates) when the phytoplankton concentration decreases (Landry 1981, Kiørboe et al. 1996). In the case of mysids, the suspension feeding mode and the raptorial mode are probably mutually exclusive, because small cladocerans are not effectively collected without a strong feeding current, whereas the feeding current will provide a fair warning signal for the hydromechanically sensing copepods.

We may ask why Praunus flexuosus switched from raptorial feeding of copepods to suspension feeding of cladocerans, and not vice versa. There are several possible explanations. First, suspension feeding on cladocerans may be energetically advantageous because the same water current that is used in swimming and respiration draws the prey to the feeding appendages. Creating a feeding current also increases encounter rates with the prey in suspension, which may be especially beneficial for littoral mysids like Praunus spp. that during daytime remain in the shadow of macroalgae. Also, small cladocerans are easier and faster to handle and ingest than copepods. For instance, an egg-carrying Eurytemora female was handled for -2 min by Neomysis integer (Viitasalo et al. 1998), whereas Bosmina spp. can be swallowed whole (whole Bosmina spp. individuals have been found in the guts of Mysis spp.; M. Viherluoto pers. comm.).

When the mysids were provided 2 copepod prey species at the same time (Acartia spp. and Eurytemora affinis), prey switching did not occur. This is plausible because both copepod species need to be captured raptorially, and so a behavioural exclusion of the other prey type will not take place. On the other hand, in the presence of $E$. affinis, the clearance of Acartia spp. was significantly lower than found in the single prey experiments. It is possible that the large body and egg sac of $E$. affinis females, or the hydrodynamic disturbance the species produces, stimulated Praunus flexuosus to make frequent unsuccessful attacks on the evasive $E$. affinis. In accordance, Ramcharan et al. (1985) found that Mysis relicta most frequently attacked Limnocalanus macrurus and Senecella calanoides (which were the largest prey available), although they never captured $S$. calanoides and caught L. macrurus in $4 \%$ of the attempts only.

In summary, we suggest that the selectivity of Praunus flexuosus increases with increasing prey availability. At low prey concentrations, $P$, flexuosus feeds flexibly and opportunistically by using both suspension and raptorial feeding modes. The apparent 'selectivity' thus mainly reflects the escape capabilities and morphological defences of the different prey species. At high prey concentrations, in turn, P. flexuosus may show true prey selection by switching behaviourally to suspension feeding on cladocerans. If copepods are the only prey type available, the total ingestion depends on how frequently the mysids are stimulated to unsuccessfully attack the more evasive prey species.

\section{Implications for Baltic plankton communities}

Our results show that all prey species are not equally profitable for Praunus flexuosus. Small cladocerans were preyed on more efficiently than copepods, and 
Acartia spp. were easier to prey on than Eurytemora affinis. This implies that long-term changes in the proportions of these taxa may affect the food gain of $P$. flexuosus, and possibly also other Baltic mysid species. In this context we note that many crustacean zooplankton species respond to variations in Baltic hydrography. An increase in water temperature and stratification and lowering of salinity favour small cladocerans (Bosmina longispina maritima and Pleopsis polyphemoides), whereas a decrease in water stratification and an increase in water salinity favour neritic copepod species, such as Pseudocalanus elongatus, Temora longicornis and Centropages hamatus (Vuorinen \& Ranta 1987, Lumberg \& Ojaveer 1991, Viitasalo et al. 1995). Our experimental results therefore imply that a decrease in salinity might improve food conditions for Baltic mysids, due to the associated increase of easily preyed on cladocerans.

The matter is not simple, however. Mysids do not feed exclusively on zooplankton, and the hydrographical changes that favour cladocerans (increase in temperature and lowering of salinity), also tend to favour Eurytemora affinis and disfavour the neritic copepods. E. affinis was shown to be difficult prey for mysids, whereas Pseudocalanus elongatus and Temora longicornis are less evasive than E. affinis and Acartia spp. (Mohammadian et al. 1997, Viitasalo et al. 1998, present study, Viitasalo unpubl.). Therefore, we suggest that long-term changes in hydrography may have different effects on shallow water and open sea mysids. In shallower archipelago areas, a decline in salinity and increase in water temperature and stability would increase the biomass of the easily preyed on Pleopsis polyphemoides and intermediately profitable Bosmina longispina maritima, which would benefit the littoral mysids Praunus spp. and Neomysis integer. In the open sea, where $P$. polyphemoides is not as abundant as in coastal areas (e.g. Viitasalo 1992), similar hydrographical changes would favour $B$. longispina maritima and the evasive $E$. affinis, and disfavour the less evasive neritic copepods. This might lead to a decrease of zooplankton in the diet of the open sea mysids Mysis mixta and $M$. relicta.

Acknowledgements. This study was conducted at the Tvärminne Zoological Station, University of Helsinki, and was financed by grants from the Academy of Finland (to M.V.) and the Walter and Andrée de Nottbeck Foundation (to M.R.). M. Lindström and the Danish Institute for Fisheries Research generously lended some of the video analysis equipment. $T$. Sjöblom skilfully constructed the plankton wheel. J. Flinkman is thanked for technical assistance. Insightful discussions and helpful comments by T. Kiørboe, H. Salemaa, I. Vuorinen and 4 anonymous referees are gratefully acknowledged. This study is dedicated to the warmest July of the century, spent entirely in the $13^{\circ} \mathrm{C} \mathrm{cool} \mathrm{room.}$

\section{LITERATURE CITED}

Bowers JA, Grossnickle NE (1978) The herbivorous habits of $M Y^{-}$ sis relicta in Lake Michigan. Limnol Oceanogr 23:767-776

Bowers JA, Vanderploeg HA (1982) In situ predatory behavior of Mysis relicta in Lake Michigan. Hydrobiologia 93 $121-131$

Cooper SD, Goldman CR (1980) Opossum shrimp (Mysis relicta) predation on zooplankton. Can J Fish Aquat Sci 37 : 909-919

Drenner RW, McComas SR (1980) The roles of zooplankter escape ability and fish size selectivity in the selective feeding and impact of planktivorous fish. In: Kerfoot WC (ed) Evolution and ecology of zooplankton communities. University Press of New Hanover, New Hanover, p 587-593

Drenner RW, Strickler JR, O'Brien WJ (1978) Capture probability: the role of zooplankter escape in the selective feeding of planktivorous fish. J Fish Res Bd Can 35:1370-1373

Gardner MB (1981) Mechanisms of size selectivity by planktivorous fish: a test of hypotheses. Ecology 62:571-578

Gerritsen J, Strickler JR (1977) Encounter probabilities and community structure in zooplankton: a mathematical model. J Fish Res Bd Can 34:73-82

Greene CG (1986) Patterns of prey selection: implications of predator foraging tactics. Am Nat 128:824-839

Grossnickle NE (1982) Feeding habits of Mysis relicta-an overview. Hydrobiologia 93:101-107

Hamner WM, Carleton JH (1979) Copepod swarms: attributes and role in coral reef ecosystems. Limnol Oceanogr 24:1-14

Hansson S, Larsson U, Johansson S (1990) Selective predation by herring and mysids, and zooplankton community structure in a Baltic Sea coastal area. J Plankton Res 12: $1099-1116$

Holling CS (1959) The components of predation as revealed by a study of small-mammal predation of the European pine sawfly. Can Entomol 91:293-320

Kerfoot WC (1978) Combat between predatory copepods and their prey: Cyclops, Epischura, and Bosmina. Limnol Oceanogr 23:1089-1102

Kiørboe T, Saiz E, Vistasalo M (1996) Prey switching behaviour in the planktonic copepod Acartia tonsa. Mar Ecol Prog Ser 143:65-75

Landry MR (1981) Switching between herbivory and carnivory by the planktonic marine copepod Calanus pacificus. Mar Biol 65:77-82

Lasenby DC, Langford RR (1973) Feeding and assimilation of Mysis relicta. Limnol Oceanogr 18:280-285

Lawton $\mathrm{JH}$, Beddington $\mathrm{J}$, Bonser $\mathrm{R}$ (1974) Switching in invertebrate predators. In: Usher $M B$, Williamson $\mathrm{MH}$ (eds) Ecological stability. Chapman and Hall, London, p $141-158$

Leong RJH, O'Connell CP (1969) A laboratory study of particulate and filter feeding of the northern anchovy (Engraulis mordax). J Fish Res Bd Can 26:557-582

Lumberg A, Ojaveer E (1991) On the environment and zooplankton dynamics in the Gulf of Finland in 1961-1990. Proc Estonian Acad Sci Ecol 1:131-140

Mauchline J (1980) The biology of mysids and euphausiids. Adv Mar Biol 18:1--677

Mohammadian MA, Hansson S, De Stasio BT (1997) Are marine planktonic invertebrates food limited? The functional response of Mysis mixta (Crustacea, Mysidacea) in the Bal.tic Sea. Mar Ecol Prog Ser 150:113-119

Murdoch WW (1969) Switching in general predators: experiments on predator specificity and stability of prey populations. Ecol Monogr 39:335-354 
Nero RW, Sprules WG (1986) Predation by three glacial opportunists on natural zooplankton communities. Can J Zool 64:57-64

Nordström H (1997) Rantavyöhykkeen halkoisjalkaäyriäisten (Mysidacea) ravinnonkäyttö Itämeressä. MSc thesis, University of Helsinki, p 1-57

Pastorok RA (1981) Prey vulnerability and size selection by Chaoborus larvae. Ecology 62:1311-1324

Ramcharan CW, Sprules WG, Nero RW (1985) Notes on the tactile feeding behaviour of Mysis relicta Lovén (Malacostraca: Mysidacea). Verh Int Verein Limnol 22:3215-3219

Rudstam LG, Hansson S (1990) On the ecology of Mysis mixta (Crustacea, Mysidacea) in a coastal area of the northern Baltic proper. Ann Zool Fenn 27:259-263

Rudstam LG, Hansson S, Larsson U (1986) Abundance, species composition and production of mysid shrimps in a coastal area of the northern Baltic proper. Ophelia Suppl $4: 225-238$

Rudstam LG, Danielsson K, Hansson S, Johansson S (1989) Diel vertical migration and feeding patterns of Mysis mixta (Crustacea, Mysidacea) in the Baltic Sea. Mar Biol 101:43-52

Rudstam LG, Hansson S, Johansson S, Larsson U (1992) Dynamics of planktivory in a coastal area of the northern Baltic Sea. Mar Ecol Prog Ser 80:159-173

Salemaa H. Hietalahti V (1993) Hemimysis anomala G.O. Sars (Crustacea: Mysidacea)-immigration of a Pontocaspian mysid into the Baltic Sea. Ann Zool Fenn 30:271-276

Salemaa H, Tyystjärvi-Muuronen K, Aro E (1986) Life histories, distribution and abundance of Mysis mixta and Mysis relicta in the northern Baltic Sea. Ophelia Suppl 4:239-247

Salemaa H, Vuorinen I, Välipakka P (1990) The distribution and abundance of Mysis populations in the Baltic Sea Ann Zool Fenn 27:253-257

Salonen K (1979) A versatile method for rapid and accurate determination of carbon by high temperature combustion. Limnol Oceanogr 24:177-183

Segerstråle SG (1962) The immigration and prehistory of the glacial relicts of Eurasia and North America. A survey and

Editorial responsibility: Otto Kinne (Editor),

Oldendorf/Luhe, Germany discussion of modern views. Int Rev Ges Hydrobiol 47 $1-25$

Siegfried CA, Kopache ME (1980) Feeding of Neomysis mercedis (Holmes). Biol Bull 159:193-205

Szlauer L (1965) The refuge ability of plancton animals before models of plancton-eating animals. Pol Arch Hydrobiol 13: 89-95

Thetmeyer H, Kils U (1995) To see and not to be seen: the visibility of predator and prey with respect to feeding behaviour. Mar Ecol Prog Ser 126:1-8

Ueda H, Kuwahara A, Tanaka M, Azeta M (1983) Underwater observations on copepod swarms in temperate and subtropical waters. Mar Ecol Prog Ser 11:165-171

Uitto A, Kaitala S, Kuosa H, Pajuniemi R (1995) Effect of nutrient addition and predation of mysid shrimp (Neomysis integer) on a plankton community in a short-term enclosure experiment in the northern Baltic. Aqua Fenn 25: $23-31$

Väinölä R (1992) evolutionary genetics of marine Mysis spp. (Crustacea: Mysidacea). Mar Biol 114:539-550

Viitasalo M (1992) Mesozooplankton of the Gulf of Finland and northern Baltic Proper - a review of monitoring data. Ophelia 35:147-168

Viitasalo M, Vuorinen I, Saesmaa S (1995) Mesozooplankton dynamics in the northern Baltic Sea: implications of variations in hydrography and climate. J Plankton Res 17: $1857-1878$

Viitasalo M, Kiørboe T, Flinkman J, Pedersen LW, Visser AW (1998) Predation vulnerability of planktonic copepods: consequences of predator foraging strategies and prey sensory abilities. Mar Ecol Prog Ser (in press)

Vuorinen I, Ranta E (1987) Dynamics of marine mesozooplankton at Seili, Northern Baltic Sea, in 1967-1975. Ophelia 28:31-48

Zaret TM (1980) The effect of prey motion on planktivore choice. In: Kerfoot WC (ed) Evolution and ecology of zooplankton communities. University Press of New Hanover, New Hanover, p 594-603

Submitted: May 4, 1998; Accepted: August 24, 1998

Proofs received from author(s): November 13, 1998 